\title{
Estimation of the Highest Surface Temperature for CFRP Ablator by Raman Analysis*
}

\author{
Jun Koyanagi, ${ }^{1 \dagger}{ }^{\dagger}$ Ken-ichi HiRaI, ${ }^{2)}$ Akiko NaKazato, ${ }^{2)}$ Ryo Inoue, ${ }^{1)}$ and Takuji UbE ${ }^{1)}$ \\ ${ }^{1)}$ Department of Material Science and Technology, Tokyo University of Science, Tokyo 125-8585, Japan \\ ${ }^{2)}$ IHI AEROSPACE Co. Ltd., Tomioka, Gumma 370-2398, Japan
}

\begin{abstract}
In this study, we present a potential method to predict the highest surface temperature reached during the heating by Raman analysis for CFRP ablator, which is commonly used in aerospace fields as a material of thermal protection system. The specimens are heated using various treatments such as static heating and dynamic heating by arc jet in inert and active environments followed by Raman analysis. The results obtained in this study indicate that the relationship between the highest surface temperature and the Raman parameters is independent of the heat treatment. The estimation method suggested for the highest surface temperature is based on Raman spectroscopic analysis.
\end{abstract}

Key Words: Thermal Protection System, CFRP, Ablator, Raman Analysis, Temperature History

\section{Introduction}

It is well known that a phenolic-based carbon fiber-reinforced phenolic resin composite, referred to as phenolic CFRP herein, has excellent heat resistance and insulation, and is currently used such as a rocket nozzle material of solid rocket and a thermal protection material for re-entry spacecraft. ${ }^{1-20)}$ It is generally difficult to measure the in-situ temperature of this material in a real application, such as reentry capsules, from the ground. The unknown temperature of the material in such cases may lead to an inefficient design feedback due to the lack of validity of the simulation model relative to the actual usages. As a result, it may adversely affect the weight savings for aerospace applications; even while the weight may be reduced significantly. If the highest temperature of the ablative material can be identified after its use or test, it can efficiently support the design feedback. Moreover, the ablating behavior is very complicated, wherein recession due to erosion, expansion due to internal gas pressure, ${ }^{21)}$ and thermal deformation and pyrolysis shrinkage all coexist during heating. The highest surface temperature information is therefore indispensable, but not sufficient, to study for example the catalytic property or convective heating to the stagnation point and so on.

Phenolic CFRP is a hard-graphitization material, in which the degree of graphitization most likely changes when it is heated above its manufacturing temperature. Hence, the highest temperature a CFRP can sustain may be estimated by measuring its degree of graphitization. Once this highest temperature estimation method is established, it will be useful not only for the aforementioned applications but also for supersonic aircraft parts and various engines. ${ }^{22-24)}$ Raman analysis is a commonly used technique for the evaluation

(C) 2016 The Japan Society for Aeronautical and Space Sciences

*Received 21 March 2016; final revision received 17 June 2016; accepted for publication 20 July 2016.

†Corresponding author, koyanagi@rs.tus.ac.jp of the degree of graphitization. Tallant et al. ${ }^{25)}$ presented the temperature dependent Raman spectra for a heated rayon CFRP, which is a rayon-based carbon fiber-reinforced phenolic resin composite. The rayon-based carbon fiber has a lower thermal conductivity compared with that of the polyacrylonitrile-based carbon fiber and pitch-based carbon fiber, ${ }^{26)}$ and hence it is also a hard-graphitization carbon material similar to phenolic CFRP. The results presented by Tallant et al. for a rayon CFRP cannot be simply applied to the phenolic CFRP used in this study because Tallant et al. performed their study using static heating under an inert atmosphere, but the phenolic CFRP is usually exposed to rapid heating under ultra-high-speed airflow in an active atmosphere.

This study presents a potential method to estimate the highest surface temperature reached during the heat treatment of phenolic CFRP using Raman analysis. The phenolic CFRP consists of a phenolic-based carbon fiber and phenolic resin, and it exhibits a porous carbon structure with approximately $70 \%$ charred when heated over $1000^{\circ} \mathrm{C}$. The porous carbon material exhibits the characteristic G-band of graphite at $\sim 1580 \mathrm{~cm}^{-1}$ and the disorder induced D-band at $\sim 1360 \mathrm{~cm}^{-1}$ in a typical Raman spectrum. Here, we use the following four parameters for the Raman data analysis: the $\mathrm{D} / \mathrm{G}$ peak intensity ratio $\left(=I_{1360} / I_{1580}\right)$, full width at half maximum for the G-band and D-band, and ratio of the integrated areas of the D-band/G-band. The relationships between these four factors and the highest surface temperature of the phenolic CFRPs are discussed. Although the method is limited to estimate "the highest surface temperature," the advantage of this method is the easiness of data acquisition; e.g. we can estimate the temperature of reentry capsule any time after the reentry.

Figure 1 shows the relative location of each experiment performed in this study. First, a static heat treatment is performed under an inert atmosphere (nitrogen or argon), which is exactly similar to the experiment conducted by Tallant 
et al. ${ }^{25)}$ for an internally manufactured rayon CFRP and the phenolic CFRP. Second, a rapid heat treatment is performed for the phenolic CFRP under an inert atmosphere using the arc jet wind tunnel located at JAXA. Finally, a rapid heat treatment in an active environment (air) is also performed using the arc jet wind tunnel. Each specimen after the heat treatments is analyzed by Raman spectroscopy, and we discuss the relationships between the aforementioned four factors and surface temperature of the specimen during the heat treatments.

\section{Heat Treatment Conditions during the Specimen Preparation}

\subsection{Specimen}

The specimens used in this study are the phenolic CFRP, phenolic-based carbon fiber cloth and rayon CFRP. The phenolic CFRP is the main test specimen, which consists of a phenolic-based carbon fiber cloth and phenolic resin manu-

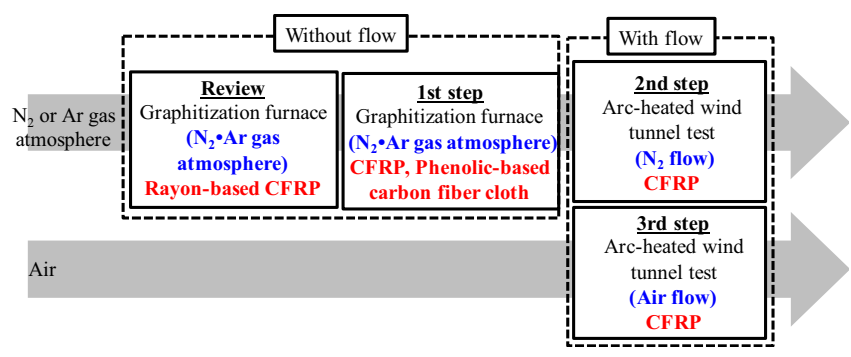

Fig. 1. Relative location of each experiment performed in this study. factured by hand-layup of semi-cured prepreg. For reference, we also investigate the phenolic-based carbon fiber cloth by itself (Gun-ei Kagaku Inc.) and rayon CFRP consisting of a rayon-based carbon fiber and phenolic resin, which is probably similar to the specimen used in Ref. 25). Due to the company's confidentiality policy, any other information, including the specimen fabrication conditions, lamination stacking sequence, and woven structure cannot be disclosed in this paper. However, the authors believe that the unknown information does not influence the results obtained in this study.

\subsection{Static heating}

Table 1 summarizes the conditions of static heat treatment, which is performed under an inert atmosphere using a graphitization furnace. For this study, a duration of approximately 30 minutes is considered to be sufficient to achieve a thermal equilibrium inside the furnace, thereby allowing us to assume that the furnace temperature is same as the specimen surface temperature. The temperature ramp rate is approximately $10-20^{\circ} \mathrm{C} / \mathrm{min}$.

\subsection{Arc jet testing in an inert atmosphere}

We only investigate the phenolic CFRP specimen by arc jet test using the planet-reentry simulating wind-tunnel facility located at the Institute of Space and Astronautical Science, Japan Aerospace Exploration Agency (ISAS/JAXA). The arc jet test is performed under an inert nitrogen environment. The test conditions and the highest surface temperature are listed in Table 2. The specimen surface temperature is measured using a radiation thermometer and the specification of the thermometer is shown in Table 3. Figure 2 presents some of the test results showing time dependence of the sur-

Table 1. Condition of heat treatment using graphitization furnace.

\begin{tabular}{|c|c|c|c|c|c|}
\hline $\begin{array}{l}\text { Number of } \\
\text { specimen }\end{array}$ & Material & $\begin{array}{l}\text { Heat treatment } \\
\text { temperature } \\
\times \text { holding time }\end{array}$ & $\begin{array}{c}\text { Rate of temperature } \\
\text { increase }\end{array}$ & Atmosphere & Equipment \\
\hline A-1 & \multirow{6}{*}{ CFRP } & $1300^{\circ} \mathrm{C} \times 2 \mathrm{~h}$ & $3^{\circ} \mathrm{C} / \mathrm{min}$ & $\mathrm{N}_{2}$ & $\begin{array}{l}\text { IHI AEROSPACE } \\
\text { Co., Ltd. }\end{array}$ \\
\hline A-2 & & $1500^{\circ} \mathrm{C} \times 0.5 \mathrm{~h}$ & \multirow{5}{*}{$\begin{array}{c}16.7^{\circ} \mathrm{C} / \mathrm{min} \\
\left(500-2500^{\circ} \mathrm{C}\right) \text {, } \\
10^{\circ} \mathrm{C} / \mathrm{min} \\
\left(\text { above } 2500^{\circ} \mathrm{C} \text { ) }\right.\end{array}$} & Vacuum & \multirow{5}{*}{$\begin{array}{l}\text { National Institute of } \\
\text { Advanced Industrial } \\
\text { Science and } \\
\text { Technology (AIST) }\end{array}$} \\
\hline A-3 & & $2000^{\circ} \mathrm{C} \times 0.5 \mathrm{~h}$ & & \multirow{4}{*}{$\mathrm{Ar}$} & \\
\hline A-4 & & $2500^{\circ} \mathrm{C} \times 0.5 \mathrm{~h}$ & & & \\
\hline A-5 & & $2750^{\circ} \mathrm{C} \times 0.5 \mathrm{~h}$ & & & \\
\hline A-6 & & $3000^{\circ} \mathrm{C} \times 0.5 \mathrm{~h}$ & & & \\
\hline B-1 & \multirow{6}{*}{$\begin{array}{c}\text { Phenolic } \\
\text { cloth }\end{array}$} & $1300^{\circ} \mathrm{C} \times 2 \mathrm{~h}$ & $3^{\circ} \mathrm{C} / \mathrm{min}$ & $\mathrm{N}_{2}$ & $\begin{array}{l}\text { IHI AEROSPACE } \\
\text { Co., Ltd. }\end{array}$ \\
\hline B-2 & & $1500^{\circ} \mathrm{C} \times 0.5 \mathrm{~h}$ & \multirow{5}{*}{$\begin{array}{c}16.7^{\circ} \mathrm{C} / \mathrm{min} \\
\left(500-2500^{\circ} \mathrm{C}\right) \text {, } \\
10^{\circ} \mathrm{C} / \mathrm{min} \\
\left(\text { above } 2500^{\circ} \mathrm{C} \text { ) }\right.\end{array}$} & Vacuum & \multirow{5}{*}{$\begin{array}{l}\text { National Institute of } \\
\text { Advanced Industrial } \\
\text { Science and } \\
\text { Technology (AIST) }\end{array}$} \\
\hline B-3 & & $2000^{\circ} \mathrm{C} \times 0.5 \mathrm{~h}$ & & & \\
\hline B-4 & & $2500^{\circ} \mathrm{C} \times 0.5 \mathrm{~h}$ & & & \\
\hline B-5 & & $2750^{\circ} \mathrm{C} \times 0.5 \mathrm{~h}$ & & $\mathrm{Ar}$ & \\
\hline B-6 & & $3000^{\circ} \mathrm{C} \times 0.5 \mathrm{~h}$ & & & \\
\hline C-1 & \multirow{6}{*}{$\begin{array}{c}\text { Rayon-based } \\
\text { CFRP }\end{array}$} & $1300^{\circ} \mathrm{C} \times 2 \mathrm{~h}$ & $3^{\circ} \mathrm{C} / \mathrm{min}$ & $\mathrm{N}_{2}$ & $\begin{array}{l}\text { IHI AEROSPACE } \\
\text { Co., Ltd. }\end{array}$ \\
\hline $\mathrm{C}-2$ & & $1500^{\circ} \mathrm{C} \times 0.5 \mathrm{~h}$ & \multirow{5}{*}{$\begin{array}{c}16.7^{\circ} \mathrm{C} / \mathrm{min} \\
\left(500-2500^{\circ} \mathrm{C}\right), \\
10^{\circ} \mathrm{C} / \mathrm{min} \\
\left(\text { above } 2500^{\circ} \mathrm{C} \text { ) }\right.\end{array}$} & Vacuum & \multirow{5}{*}{$\begin{array}{l}\text { National Institute of } \\
\text { Advanced Industrial } \\
\text { Science and } \\
\text { Technology (AIST) }\end{array}$} \\
\hline C-3 & & $2000^{\circ} \mathrm{C} \times 0.5 \mathrm{~h}$ & & & \\
\hline C-4 & & $2500^{\circ} \mathrm{C} \times 0.5 \mathrm{~h}$ & & & \\
\hline $\mathrm{C}-5$ & & $2750^{\circ} \mathrm{C} \times 0.5 \mathrm{~h}$ & & $\mathrm{Ar}$ & \\
\hline C-6 & & $3000^{\circ} \mathrm{C} \times 0.5 \mathrm{~h}$ & & & \\
\hline
\end{tabular}


Table 2. Heating condition for CFRP specimen during arc-heated wind tunnel test (under nitrogen flow condition).

\begin{tabular}{lcccc}
\hline $\begin{array}{c}\text { Number of } \\
\text { specimen }\end{array}$ & Dimensions & $\begin{array}{c}\text { Heating rate } \\
\left(\mathrm{MW} / \mathrm{m}^{2}\right)\end{array}$ & $\begin{array}{c}\text { Testing } \\
\text { time }(\mathrm{s})\end{array}$ & $\begin{array}{c}\text { Maximum surface } \\
\text { temperature }\left({ }^{\circ} \mathrm{C}\right)\end{array}$ \\
\hline CFRP_1.2_60 & $\varphi 50 \times 35 \mathrm{~mm}$ & 1.2 & 60 & 1842 \\
CFRP_6_60 & $\varphi 50 \times 35 \mathrm{~mm}$ & 6 & 60 & 2529 \\
CFRP_10_60 & $\varphi 25 \times 35 \mathrm{~mm}$ & 10 & 60 & 3034 \\
CFRP_1.2_120 & $\varphi 50 \times 35 \mathrm{~mm}$ & 1.2 & 120 & 1864 \\
CFRP_3_120 & $\varphi 50 \times 35 \mathrm{~mm}$ & 3 & 120 & 2262 \\
CFRP_6_120 & $\varphi 50 \times 35 \mathrm{~mm}$ & 6 & 120 & 2514 \\
CFRP_10_120 & $\varphi 25 \times 50 \mathrm{~mm}$ & 10 & 120 & 2989 \\
\hline
\end{tabular}

Table 3. Specification of radiation thermometer used in this study.

\begin{tabular}{lc}
\hline \multicolumn{1}{c}{ Type } & $\begin{array}{c}\text { Monochromatic radiation } \\
\text { thermometer }\end{array}$ \\
\hline Manufacturer & Mikron M-90 Vx \\
Detective waveband & $0.6 \mu \mathrm{m}$ \\
Focus diameter & $\sim \varphi 2 \mathrm{~mm}$ \\
Range of temperature & $1200-4000^{\circ} \mathrm{C}$ \\
Emissivity of the specimen & $\varepsilon=0.95$ \\
\hline
\end{tabular}

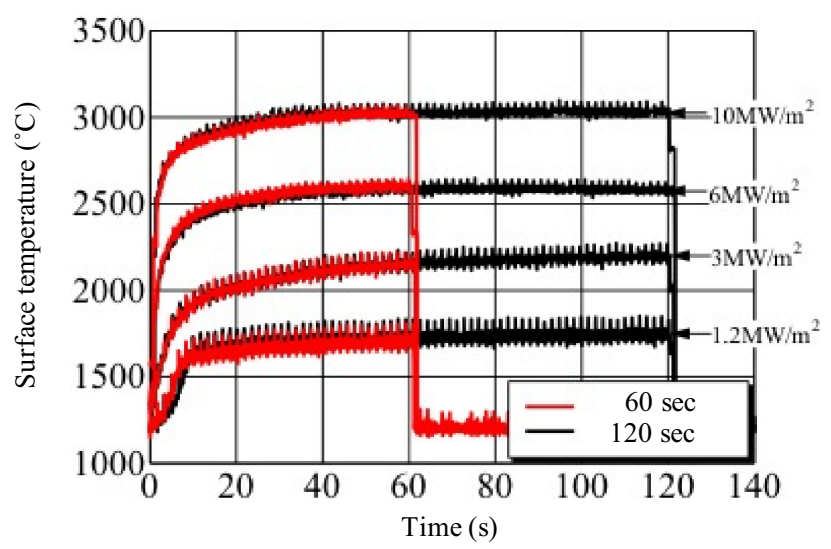

Fig. 2. Surface temperature of CFRP specimen during arc-heated wind tunnel test (under $\mathrm{N}_{2}$ gas flow condition).

face temperature during the heat treatment. The measured temperature is stable at each heating rate as shown in Fig. 2.

\subsection{Arc jet testing in an active environment}

The arc jet testing is also performed in an active environment such as air. Figure 3 shows a photograph of this heating treatment. The gas stream passing through the arc jet comes from the nozzle located to the left hand side in Fig. 3 and then flows over the specimen surface. This experiment is most similar to the exposure of an actual phenolic CFRP used as a thermal protection system material in actual usages. Table 4 shows the test conditions and the highest surface temperature reached during the arc jet test in air. Figure 4 shows the surface temperature of CFRP specimen during arc-heated wind tunnel test under air. The variation in the surface temperature is measured using a radiation thermometer. Unlike the temperature history observed for the arc jet test under an inert atmosphere shown in Fig. 2, the surface temperature is not stable at a heating rate of $10 \mathrm{MW} / \mathrm{m}^{2}$ in air as illustrated in Fig. 4. The schematic view of experimental set-up of surface-temperature measurement system is

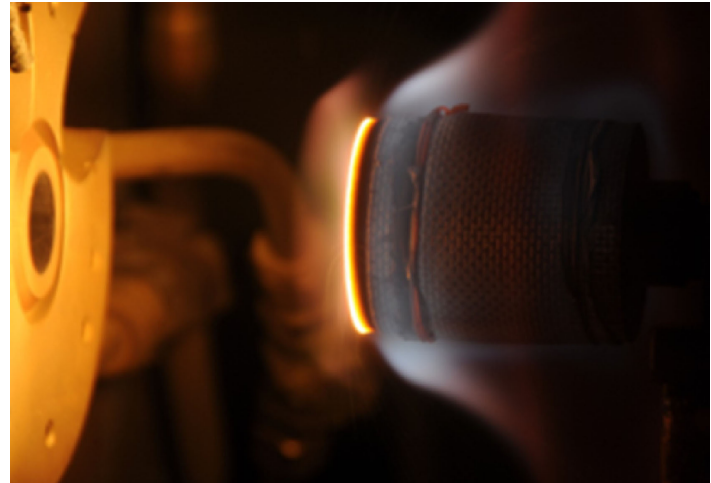

Fig. 3. Photograph of CFRP specimen during arc-heated wind tunnel test (CFRP_6_120,6 MW/m²).

Table 4. Heating condition for CFRP specimen during arc-heated wind tunnel test (under air flow condition).

\begin{tabular}{lcccc}
\hline $\begin{array}{c}\text { Number of } \\
\text { specimen }\end{array}$ & Dimensions & $\begin{array}{c}\text { Heating } \\
\text { rate } \\
\left(\mathrm{MW} / \mathrm{m}^{2}\right)\end{array}$ & $\begin{array}{c}\text { Testing } \\
\text { time }(\mathrm{s})\end{array}$ & $\begin{array}{c}\text { Maximum } \\
\text { surface } \\
\text { temperature } \\
\left({ }^{\circ} \mathrm{C}\right)\end{array}$ \\
\hline CFRP_1.2_60_N & $\varphi 50 \times 35 \mathrm{~mm}$ & 1.2 & 60 & 1809 \\
CFRP_3_60_N & $\varphi 50 \times 35 \mathrm{~mm}$ & 3 & 60 & 1851 \\
CFRP_6_60_N & $\varphi 50 \times 35 \mathrm{~mm}$ & 6 & 60 & 2218 \\
CFRP_10_60_N & $\varphi 25 \times 35 \mathrm{~mm}$ & 10 & 60 & 2273 \\
CFRP_1.2_120_N & $\varphi 50 \times 35 \mathrm{~mm}$ & 1.2 & 120 & 2646 \\
CFRP_3_120_N & $\varphi 50 \times 35 \mathrm{~mm}$ & 3 & 120 & 2648 \\
CFRP_6_120_N & $\varphi 50 \times 35 \mathrm{~mm}$ & 6 & 120 & 3072 \\
CFRP_10_120_N & $\varphi 25 \times 50 \mathrm{~mm}$ & 10 & 120 & 3100 \\
\hline
\end{tabular}

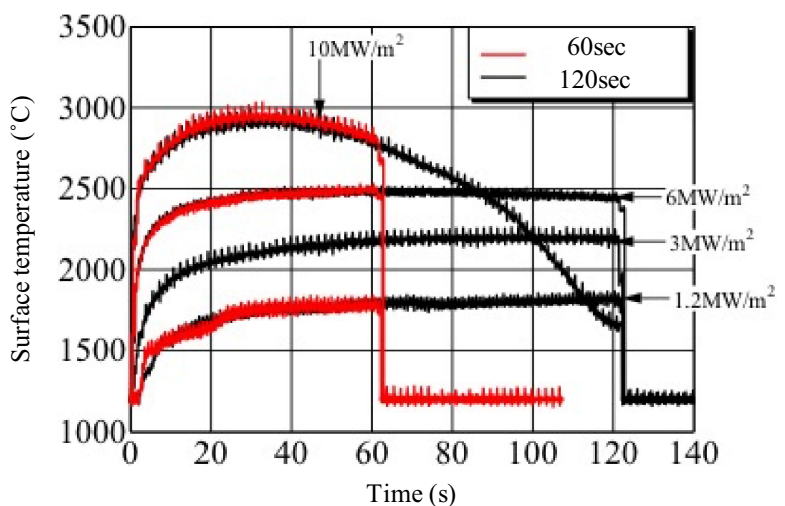

Fig. 4. Surface temperature of CFRP specimen during arc-heated wind tunnel test (under air flow condition).

shown in Fig. 5. The light gray part is the specimen and the orange part behind the specimen is a thermal insulator used for this test. The phenolic CFRP specimen shows a recession, which is a surface regression due to the oxidation in air resulting in an unstable surface temperature. During the active oxidation state, the recession is rapid and the radiation thermometer goes out of focus. As a result, the surface temperature measurement may not be correct, and therefore this study regards the results of specimen heated at $10 \mathrm{MW} / \mathrm{m}^{2}$ in an active environment as reference data. The actual surface temperature is expected to be higher than that measured but we take the maximum value of Fig. 4 in the present study. 


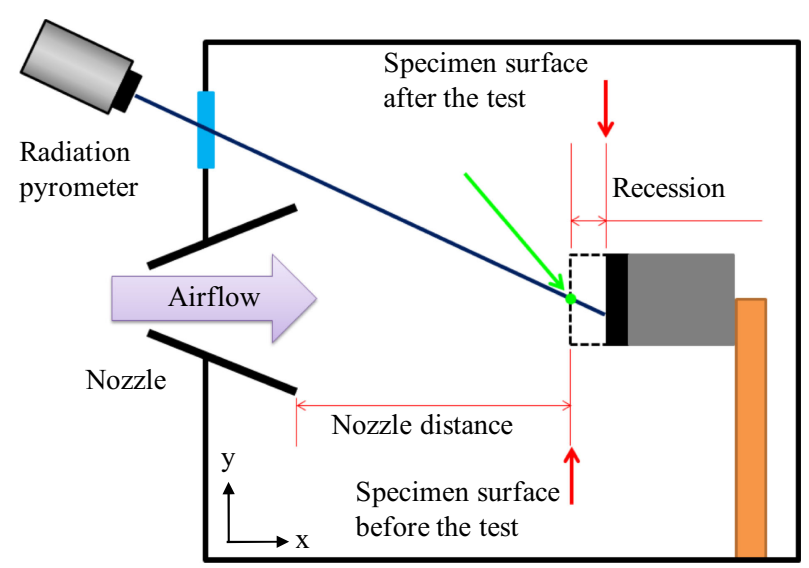

Fig. 5. Experimental set up of surface temperature measurement system for arc-heated wind tunnel test.

Table 5. Measurement condition of Raman spectrum.

\begin{tabular}{lc}
\hline \multicolumn{1}{c}{ Equipment } & Jobin-Yvon T64000 \\
\hline Measurement range & $250-3400 \mathrm{~cm}^{-1}$ \\
Exposure time & $25 \mathrm{~s}$ \\
Accumulation time & 2 times \\
Excitation source & Ar laser $(514.527 \mathrm{~nm})$ \\
Beam diameter & $1 \mu \mathrm{m}$ \\
Power of laser & $1 \mathrm{~mW}$ \\
Grating & $1800 \mathrm{gr} / \mathrm{mm}$ \\
Detector & Liquid nitrogen-cooled CCD \\
\hline
\end{tabular}

\section{Raman Analysis}

\subsection{Measurement conditions}

For this study, the Raman spectra are measured using a T64000 Raman system (JOBIN YVON Inc.) located at the Tokyo City University. The specification of the Raman system is shown in Table 5. The argon laser was focused with a $1 \mu \mathrm{m}$ diameter on the specimen surfaces and we obtained Raman spectra. As shown in Fig. 6, measured points are determined at the carbon fiber on the surface using optical microscope; the measurement point is inside of the spot where the surface temperature measured by the pyrometer.

For the Raman peak parameter analysis, all observed peaks are assigned as Fig. 7(a). ${ }^{27,28)}$ In this study, we focused on the peak 1 and peak 2, i.e. D-band and G-band, respectively. At first, a baseline is obtained in the range of $250-3400 \mathrm{~cm}^{-1}$, the measured spectra are then peak-fitted by using the Lorentzian functions, as shown in Fig. 7(a) for an example. Next, the $\mathrm{D} / \mathrm{G}$ relative intensity ratio ( $=I_{1360} / I_{1580}$ ), full width at half maximum (FWHM) for the G-band and D-band, and ratio of the integrated areas of the D-band/G-band are calculated, as indicated in Fig. 7(b).

\subsection{Results and discussion}

Before describing results, the four Raman parameters introduced in this study are meaningfully explained here. First of all, $I_{1360} / I_{1580}$ will decrease when SP3 bonding decreases and SP2 bonding increases. Hence, the values is expected to decrease with temperature. FWHM of D-band will decrease when SP3 bonding regarding amorphous region decreases.

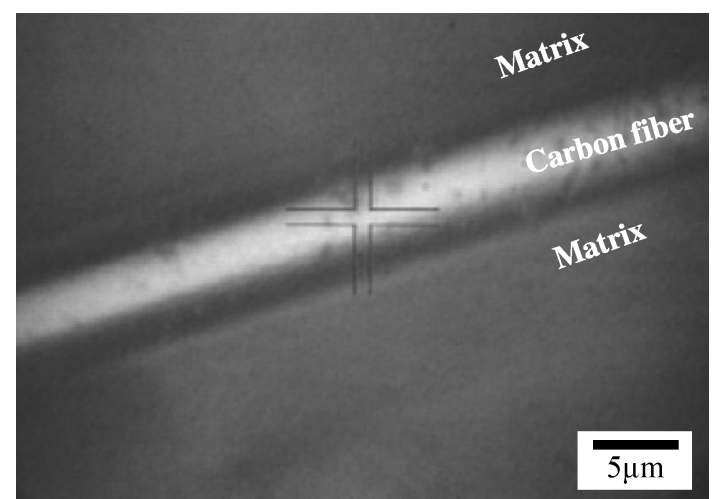

Fig. 6. Micrograph of carbon fiber observed using objective lens equipped with laser Raman spectroscopy system.
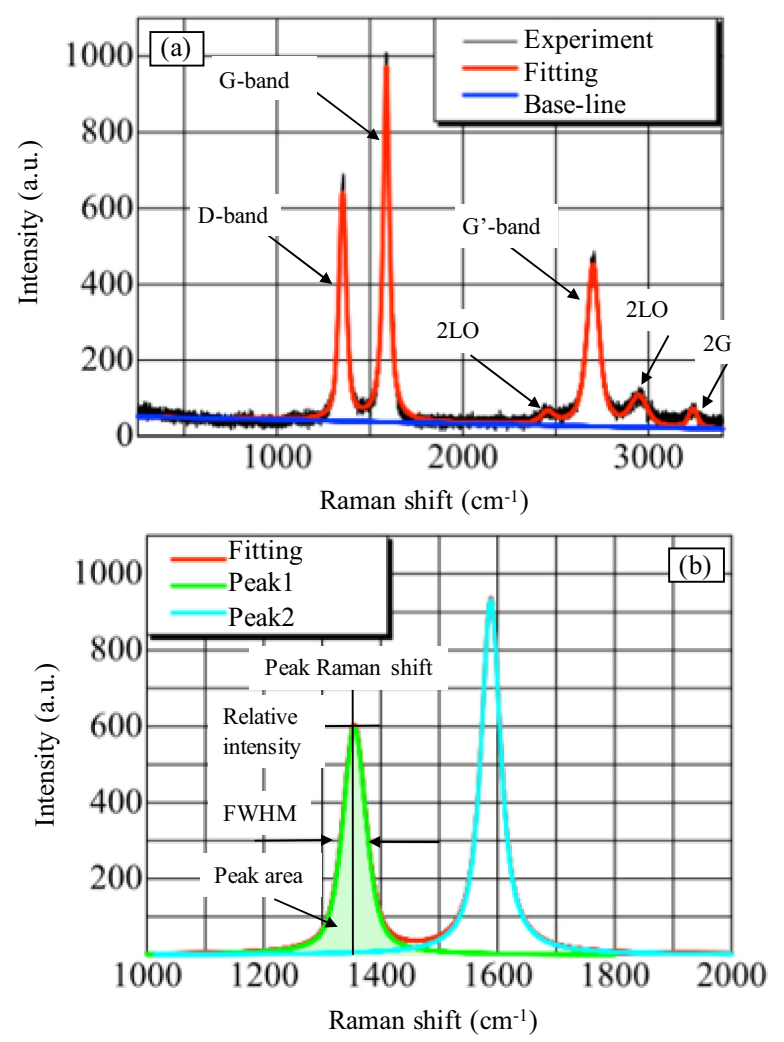

Fig. 7. (a) A typical observed Raman spectrum with base line and Lorenztian curve fitting. (b) Definition of Raman parameters used in this research.

FWHM of G-band will decrease when graphite-like SP2 bonding increases. The ratio of the integrated areas of the D-band/G-band indicates broad ratio of D-band/G-band, not limiting amorphous and graphite.

It should be noted that the results and discussions mentioned hereafter are limited at the case for which each constant heating rate is kept over $60 \mathrm{~s}$. This is not realistic heating environment when we assume reentry in which heating rate changes with time, and this discussion is intended for a baseline for estimating method of the highest temperature. The authors are not sure this discussion is applicable when heating time is shorter than $60 \mathrm{~s}$.

Figure 8 compares the four peak parameters presented by Tallant et al. ${ }^{25)}$ with those obtained in this study for the rayon 

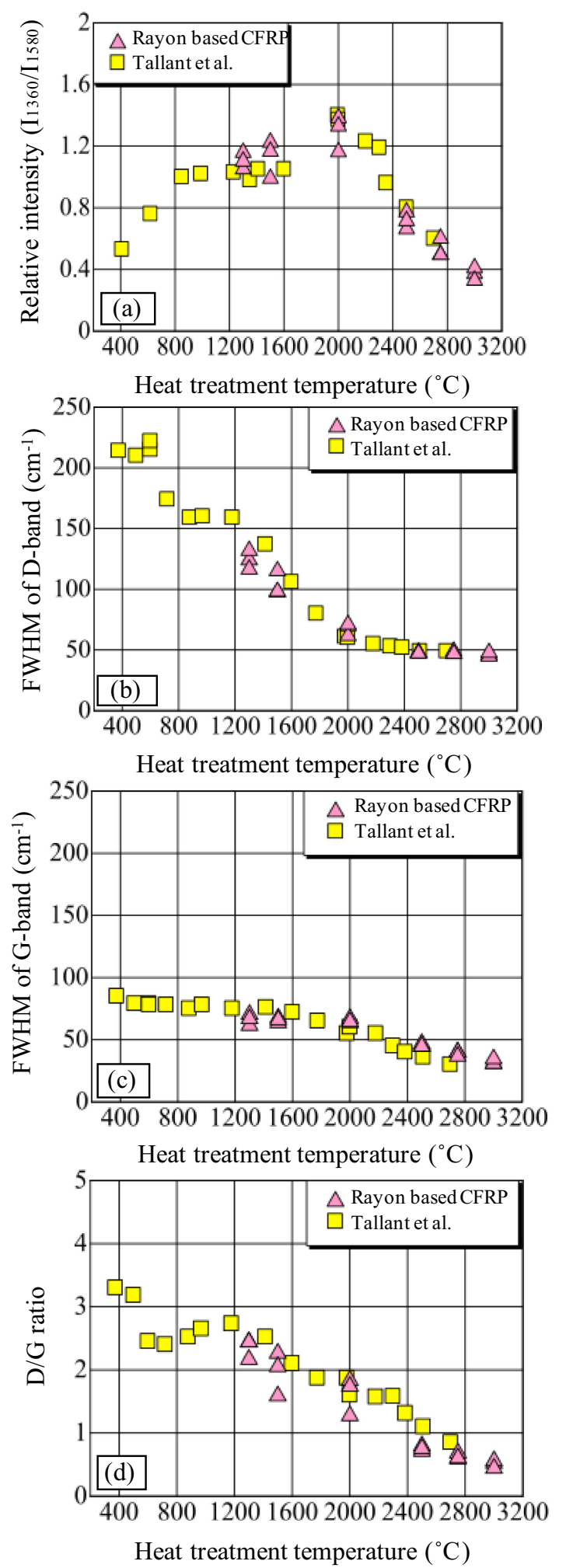

Fig. 8. Raman parameters of rayon-based CFRPs after static heating. For comparison purpose, experimental results reported by Tallant et al. ${ }^{25)}$ are also shown in the figure. (a) Relative intensity, (b) FWHM of D-band, (c) FWHM of G-band and (d) D/G ratio.

CFRP. Although these results (Ref. 25) and ours are obtained using different heat treatments, the relationships between the four peak parameters and specimen temperature in both cases are quantitatively similar. Both studies show that the maximum value of the $D / G$ peak intensity ratio is around $2000^{\circ} \mathrm{C}$, and the FWHM values of the G-band and D-band gradually decrease with increasing temperature.

Next, we compare the relationships between the four peak parameters and specimen temperature for the phenolic CFRP and phenolic-based carbon fiber cloth with those reported in Ref 25). Figure 9 indicates that the results for all three materials agree well with each other in spite of the different type of carbon fiber. Thus, we confirm that there is a relationship between the four Raman parameters and heat treatment temperature during static heating under an inert atmosphere, and the rayon CFRP and phenolic CFRP exhibit similar temperature dependent behaviors for same peak parameters.

Finally, the relationships between specimen temperature and the four Raman parameters calculated after static heating are compared with those calculated after arc jet testing under active and inert conditions for the phenolic CFRP (Fig. 10). Note the data presented in Fig. 10 ranges very widely from the static heat treatment under an inert atmosphere to arc jet testing in an active environment under dynamic pressure due to the arc-jet flow rate and oxidation phenomenon. This study confirms that the heating method does not significantly affect the relationship between the highest surface temperature and the four Raman parameters determined from the peak-fitted spectra.

Based on the experimental results (Figs. 8-10), this study suggests a potential method to estimate the highest surface temperature for the phenolic CFRP. Below $2000^{\circ} \mathrm{C}$, the full width at half maximum of the D-band is relatively more sensitive to the specimen temperature. For example, with temperature increase from $1000^{\circ} \mathrm{C}$ to $2000^{\circ} \mathrm{C}$, FWHM of Dband is reduced to one-third, which is the most sensitive response among the four parameters. We shall suggest it can be used to estimate the highest surface temperature of this range. On the other hand, the $\mathrm{D} / \mathrm{G}$ peak intensity ratio shows a strong temperature dependence above $2000^{\circ} \mathrm{C}$; it becomes to one-third or quarter as temperature increases from $2000^{\circ} \mathrm{C}$ to $3000^{\circ} \mathrm{C}$, which is the most significant decrease. The $\mathrm{D} / \mathrm{G}$ peak intensity ratio can be used as an indicator to predict the specimen temperature. For both indicators, when their values are given, we can estimate the highest temperature with scattering of $200^{\circ} \mathrm{C}$ or little more on a consideration of the results. Hence, using the two Raman parameters, i.e., the D/ G peak intensity ratio and FWHM of the D-band, we can probably estimate the highest surface temperature of the phenolic CFRP after the use. It should be noted also that this result is applicable only when the constant heating rate is kept no less than $60 \mathrm{~s}$.

\section{Conclusion}

In this study, we investigate a potential method to predict the highest specimen temperature by Raman spectroscopy for the phenolic CFRP, which is used as a thermal protection system material in the aerospace industry. Three specimens used for this study include the phenolic CFRP composed of a phenolic-based carbon fiber cloth and phenolic resin, phenolic-based carbon fiber cloth and rayon CFRP consist- 

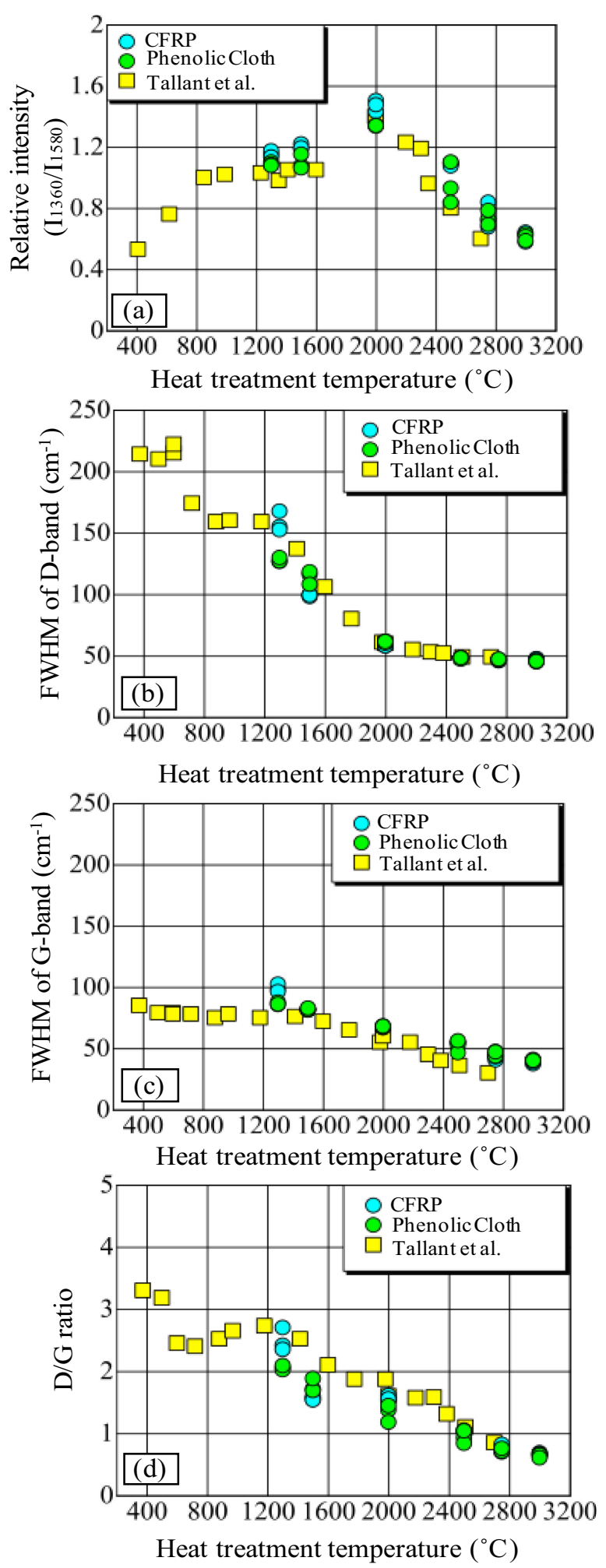

Fig. 9. Raman parameters of phenolic CFRPs and phenolic-based carbon fiber cloth after static heating under $\mathrm{N}_{2}$ or Ar gas atmosphere.

For comparison purpose, experimental results reported by Tallant et al. ${ }^{25)}$ are also shown in the figure. (a) Relative intensity, (b) FWHM of D-band, (c) FWHM of G-band and (d) D/G ratio.

ing of a rayon-based carbon fiber and phenolic resin. The test specimens are heat treated by static and dynamic heating in inert and active environments followed by the Raman spectroscopy peak parameter analysis. All of the specimens show similar temperature dependent behavior of the four Raman
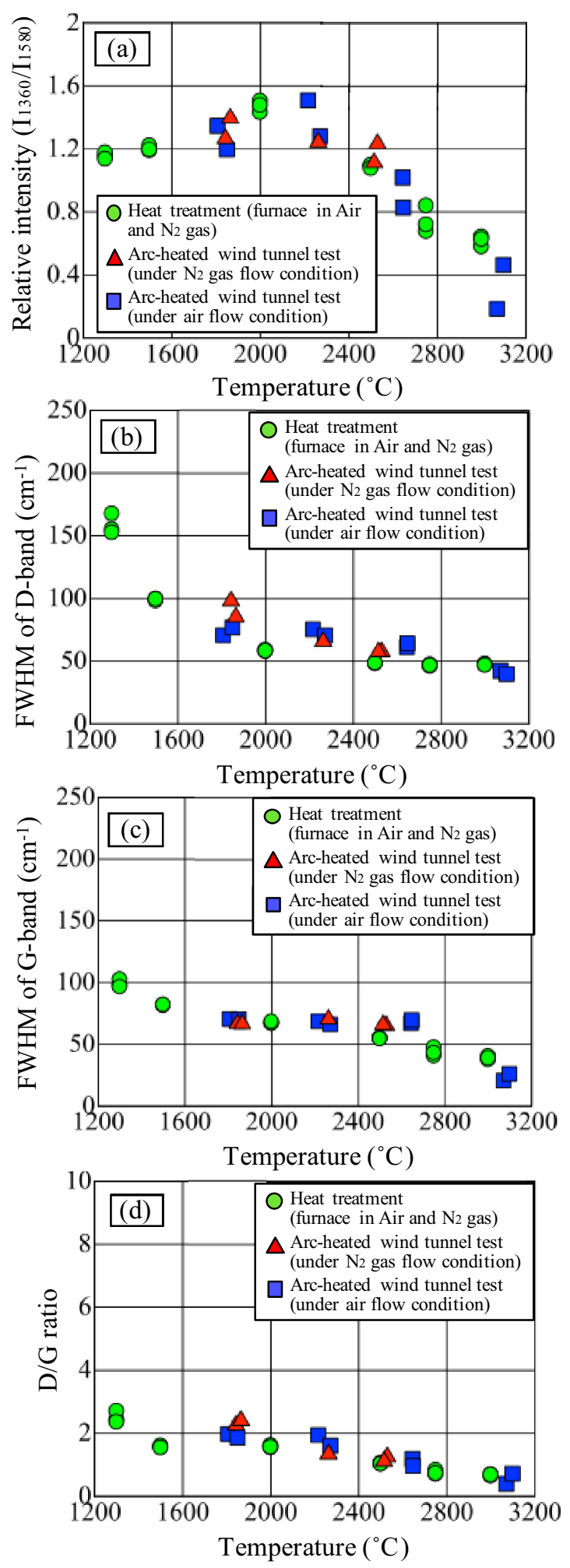

Fig. 10. Raman parameters of phenolic CFRPs after static heating and arc jet testing under air and $\mathrm{N}_{2}$ insert gas atmosphere.

(a) Relative intensity, (b) FWHM of D-band, (c) FWHM of G-band and (d) $\mathrm{D} / \mathrm{G}$ ratio.

parameters. It is found that the heat treatment temperature, which is kept over $60 \mathrm{~s}$, shows a relatively clear correlation with the full width at half maximum of the D-band up to $2000^{\circ} \mathrm{C}$ and then with the $\mathrm{D} / \mathrm{G}$ peak intensity ratio above $2000^{\circ} \mathrm{C}$. Thus, this study presents a temperature prediction 
method for the phenolic CFRP used over a wide temperature range.

\section{Acknowledgments}

The authors express sincere gratitude to Prof. Yoshida and Dr. Shindo, Tokyo City University for assistance with the Raman spectral measurements and providing useful comments. We acknowledge the National Institute of Advanced Industrial Science and Technology (AIST) for giving us the opportunity to use the graphitization furnace. We also thank the Institute of Space and Astronautical Science, Japan Aerospace Exploration Agency (JAXA/ISAS) for giving us the access to use the planet-reentry simulating windtunnel facility.

\section{References}

1) Ahn, H. K., Park, C., and Sawada, K.: Response of Heatshield Material at Stagnation Point of Pioneer-Venus Probes, J. Thermophys. Heat Transfer., 16, 3 (2002), pp. 432-439.

2) Szasz, B. A. and Okuyama, K.: A New Method for Estimating the Mass Recession Rate for Ablator System, Int. J. Mech. Aerospace, Ind. Mechatronics Eng., 8, 11 (2014), pp. 1843-1847.

3) Tran, H. K.: Development of Lightweight Ceramic Ablators and ArcJet Test Results, NASA TM-108798, 1994.

4) Schneider, P. J., Dolton, T. A., and Reed, G. W.: Mechanical Erosion of Charring Ablators in Ground-Test and Re-Entry Environments, AIAA J., 6, 1 (1968), pp. 64-72.

5) Tran, H., Johnson, C. E., Rasky, D. J., Hui, F. C., Hsu, M. T., Chen, T., Chen, Y. K., Paragas, D., and Kobayashi, L.: Phenolic Impregnated Carbon Ablators (PICA) as Thermal Protection Systems for Discovery Missions, NASA TM-110440, 1997.

6) Tran, H., Rasky, D. J., and Esfahani, L.: Thermal Response and Ablation Characteristics of Lightweight Ceramic Ablators, Spacecraft Rockets, 31, 6 (1994), pp. 993-998.

7) Yamada, T., Inatani, Y., and Hirai, K.: Thermal Responses of Ablator for Reentry Capsules with Supraorbital Velocity, The Institute of Space and Astronautical Science Report, SP(17), 2003.

8) Dimitrienko, Yu. I.: Thermomechanical Behavior of Composite Materials and Structures under High Temperatures: 1. Materials, Composites Part A Appl. Sci. Manufacturing, 28, 5 (1997), pp. 453-461.

9) Yamada, T., Ishii, N., Inatani, Y., and Honda, M.: Thermal Protection System of the Reentry Capsule with Superorbital Velocity, The Institute of Space and Astronautical Science Report, SP(17), 2003, pp. 245-261.

10) Trick, K. A., Saliba, T. E., and Sandhu, S. S.: A Kinetic Model of the Pyrolysis of Phenolic Resin in a Carbon/Phenolic Composite, Carbon, 35, 3 (1997), pp. 393-401.

11) Trick, K. A. and Saliba, T. E.: Mechanisms of the Pyrolysis of Phenolic Resin in a Carbon/Phenolic Composite, Carbon, 33, 11 (1995), pp. 1509-1515.

12) Kubota, Y., Fukuda, K., Hatta, H., Wernitz, R., Herdrich, G., and Fasoulas, S.: Comparison of Thermal Deformations of Carbon FiberReinforced Phenolic Matrix Ablators by Arc-Plasma Wind Tunnel Heating and Quasi-Static Heating, Adv. Compos. Mater., 24, 2 (2015), pp. 179-195.

13) Schulte-Fischedick, J., Zern, A., Mayer, J., Ruhle, M., and
Voggenreiter, H.: The Crack Evolution on the Atomistic Scale during the Pyrolysis of Carbon Fibre Reinforced Plastics to Carbon/Carbon Composites, Composites Part A, 38 (2007), pp. 2237-2244.

14) Schulte-Fischedick, J., Zern, A., Mayer, J., Ruhle, M., and Voggenreiter, H.: The Crack Development on the Micro- and Mesoscopic Scale during the Pyrolysis of Carbon Fibre Reinforced Plastics to Carbon/Carbon Composites, Composites Part A, 38 (2007), pp. 2171-2181.

15) Suzuki, K., Fujita, K., and Abe, T.: Chemical Nonequilibrium Viscous Shock-Layer Analysis over Ablating Surface of Superorbital Re-Entry Capsule, The Institute of Space and Astronautical Science Report, SP(17), 2003, pp. 23-42.

16) Suzuki, T., Sawada, K., Yamada, T., and Inatani, Y.: Experimental and Numerical Study of Pyrolysis Gas Pressure in Ablating Test Piece, $J$. Thermophys. Heat Transfer, 19, 3 (2005), pp. 266-272.

17) Suzuki, T., Sawada, K., Yamada, T., and Inatani, Y.: Gas Permeability of Oblique-Layered Carbon-Cloth Ablator, J. Thermophys. Heat Transfer, 18, 4 (2004) pp. 548-550.

18) Ahn, H. K., Park, C., and Sawada, K.: Response of Heatshield Material at Stagnation Point of Pioneer-Venus Probes, J. Thermophys. Heat Transfer, 16, 3 (2002), pp. 432-439.

19) Ishihara, T., Ogino, Y., Ohnishi, N., and Tanno, H.: Numerical Study on Abnormal Heat Flux Augmentation in High Enthalpy Shock Tunnel (HIEST), T. Jpn. Soc. Aeronaut. Space Sci., 58 (2015), pp. 319-326.

20) Takayanagi, H., Mizuno, M., Fujii, K., Sakai, T., and Fujita, K.: Application of Two-Photon Absorption Laser-Induced Fluorescence to Atomic Species in the JAXA $750 \mathrm{~kW}$ Arc-Heated Wind Tunnel, $T$. Jpn. Soc. Aeronaut. Space Sci., 57 (2014), pp. 101-108.

21) Koyanagi, J., Fukuda, Y., Yoneyama, S., Hirai, K., Yoshimura, A., Aoki, T., and Ogasawara, T.: Local Out-of-Plane Deformation of CFRP Ablator Subjected to Rapid Heating, Adv. Compos. Mater., (in press).

22) Tani, K., Hasegawa, S., Ueda, S., Kanda, T., and Nagata, H.: Analytical Method for Prediction of Suction Performance of Ejector-Jet, T. Jpn. Soc. Aeronaut. Space Sci., 58 (2015), pp. 228-236.

23) Matsuno, Y., Tsuchiya, T., Imamura, S., and Taguchi, H.: Multidisciplinary Design Optimization of Long or Short Range Hypersonic Aircraft, T. Jpn. Soc. Aeronaut. Space Sci., 57 (2014), pp. 143-152.

24) Nakano, M., Hosoda, S., and Nishiyama, K.: Sputtering Yield of Cabon-Carbon Composite Due to Xenon Ion Bombardment in Ion Engines, T. Jpn. Soc. Aeronaut. Space Sci., 58 (2015), pp. 213-219.

25) Tallant, D. R., Auerbach, I., and Higgins, K. L.: Evaluation and Mapping of Heat-Shield Flight Temperature and Composition with Raman Spectroscopic Techniques, Appl. Spectroscopy, 49, 5 (1995), pp. 598-604.

26) Rossi, R. C. and Wong, W. C.: Availability of Aerospace Rayon for SRM Nozzle Insulators, AIAA 1995, 1995, pp. 1-6.

27) Brar, V. W., Samsonidze, G. G., Dresselhaus, M. S., Dresselhaus, G., Saito, R., Swan, A. K., Unlu, M. S., Goldberg, B. B., Souza, A. G., and Jorio, A.: Second-Order Harmonic and Combination Modes in Graphite, Single-Wall Carbon Nanotube Bundles, and Isolated Single-Wall Carbon Nanotubes, PRB, 66 (2002), 155418.

28) Shimada, T., Sugai, T., Fantini, C., Souza, M., Cançado, L. G., Jorio, A., Pimenta, M. A., Saito, R., Grüneis, A., and Dresselhaus, G.: Origin of the $2450 \mathrm{~cm}^{-1}$ Raman Bands in HOPG, Single-Wall and DoubleWall Carbon Nanotubes, Carbon, 43 (2005), pp. 1049-1054.

T. Ogasawara Associate Editor 